\title{
A ÉTICA COMO FILOSOFIA PRIMEIRA: UMA ANÁLISE FILOSÓFICA DE MINEIRINHO DE CLARICE LISPECTOR
}

\author{
LA ÉTICA COMO FILOSOFÍA PRIMERA: UN ANÁLISIS FILOSÓFICO DEL MINEIRINHO POR \\ CLARICE LISPECTOR
}

\author{
Lourival Robty Santos de Souza* \\ David de Souza Fernandes**
}

\begin{abstract}
RESUMO
A proposta geral desta pesquisa consiste em analisar a crônica "Mineirinho", escrita por Clarice Lispector a partir da perspectiva da filosofia de Emmanuel Lévinas em que ele afirma que a ética é a filosofia primeira. Trata-se, em um primeiro momento, em delinear a filosofia levinasiana e seus principais conceitos, como ética, alteridade, rosto, para que se possa relacionar com a narrativa de Clarice Lispector e sua aspiração literária e o seu filosofar diante de um cenário em que encontrou um homem assassinado por seus crimes e uma justiça humana falha, incapaz de conceber Mineirinho como um ser humano. A ética surge como uma chave de leitura para a análise textual por engendrar uma cultura que valora o ser humano e que pode propiciar também uma nova atitude ao comportamento do sujeito que está inserido em um ambiente coletivo, melhorando, ao que acredita-se, a existência do outro no mundo. Tentar-se-á demonstrar como Lispector e Lévinas convergem quando denunciam a desumanização nas relações interpessoais.

PALAVRAS-CHAVE: Ética. Alteridade. Filosofia. Clarice Lispector. Literatura.
\end{abstract}

\section{RESUMEN}

El propósito general de esta investigación es analizar la crónica O Mineirinho, escrita por Clarice Lispector desde la perspectiva de la filosofía de Emmanuel Lévinas en la que afirma que la ética es la primera filosofía. En primer lugar, se trata de delinear la filosofía levinasiana y sus conceptos principales, como la ética, la alteridad, el rostro, para que pueda relacionarse con la narrativa de Clarice Lispector y su aspiración literaria y su filosofía antes de un escenario en quien encontró a un hombre asesinado por sus crímenes y una justicia humana fallida, incapaz de concebir a Mineirinho como un ser humano. La ética surge como una clave de lectura para el análisis textual porque engendra una cultura que valora a los seres humanos y también puede proporcionar una nueva actitud ante el comportamiento del sujeto que se inserta en un entorno colectivo, mejorando lo que se cree existencia del otro en el mundo. Intentaremos demostrar cómo convergen Lispector y Lévinas cuando denuncian la deshumanización en las relaciones interpersonales.

PALABRAS CLAVE: Ética. Alteridad. Filosofía. Clarice Lispector. Literatura.

\footnotetext{
* Graduado em Filosofia pelo Instituto Santo Tomás de Aquino e pós-graduado em aconselhamento filosófico pelo Claritiano Centro Universitário. Email: lourivalrobty@ gmail.com.

** Graduado em Filosofia pelo Instituto Santo Tomás de Aquino e graduando em Direito pela Faculdade Ari de Sá. E-mail: sf.df.david@gmail.com.
} 


\section{A ÉTICA COMO FILOSOFIA PRIMEIRA: UMA ANÁLISE FILOSÓFICA DE "MINEIRINHO" DE CLARICE LISPECTOR}

A intenção deste trabalho é analisar o trajeto literário da crônica "Mineirinho" - escrita por Clarice Lispector - a partir da perspectiva do filósofo Emmanuel Lévinas que investiga e propõe à própria Filosofia o fundamento de que a ética seja a filosofia primeira. Ao esclarecer filosoficamente essa proposta do filósofo da alteridade, tentar-se-á realizar uma leitura da crônica sob a ótica da ética, visto que Rosenbaum (2010) corrobora essa possibilidade, "por situar-se, portanto, nessa dupla face - psicológicalexistencial e éticolpolítica -, 'Mineirinho' demanda um olhar abrangente, capaz de acompanhar sua múltipla significação" (ROSENBAUM, 2010, p. 01).

A ética surge como uma chave de leitura para a análise textual por engendrar uma cultura que valora o ser humano e que pode propiciar também uma nova atitude ao comportamento do sujeito que está inserido no "nós" enquanto uma coletividade social, melhorando, ao que acredita-se, a existência do outro no mundo.

\section{A ÉTICA COMO FILOSOFIA PRIMEIRA}

Antes de chegar à conclusão da ética como filosofia primeira, Lévinas encabeça seu fundamento por meio da crítica à filosofia ocidental que está construída sob a ideia de que apenas se chega à transcendência pelo caminho do conhecimento (LOVO, 1999). Ou seja, um conhecimento que é adquirido pelo sujeito no momento em que ele entra em contato com o outro, submetendo-o a uma relação sujeito-objeto. Na investida contra esse modo de pensar, o filósofo afasta-se totalmente dessa estrutura do conhecimento e propõe o esquema EUOUTRO.

Eu-Outro, em que há uma descentralização do eu e da consciência enquanto eu me devo ao outro e é o outro quem constitui meu eu. Pois o outro sempre precede minha subjetividade. [...] Isso abre a possibilidade de acesso a uma verdadeira transcendência. Transcendência que significa não o domínio do outro, mas o respeito pelo outro e onde o ponto de partida para o pensamento não é mais o ser, mas o outro. [...] Então, uma relação transcendente deve ser - segundo Levinas uma relação desinteressada no sentido moral e metafísico. (LOVO, 1999, p. 5-6, tradução nossa).

O outro é responsável em romper o invólucro que preservava o ser do sujeito das situações de relação. A razão não é mais o determinador das relações, - ela que garantiu 
outrora a primazia do esquema sujeito-objeto - e sim o contato, o face a face, o instante da iminência ética. Nessa nova perspectiva, ao outro se atribui a tarefa de inaugurar o sujeito ou o "yo" (eu) na relação com o outro. Sendo assim,

\begin{abstract}
Nesse contexto, a ética aparece como a única via para a saída do ser. Assim, a relação com o outro é uma relação ética, uma relação de ordem diferente do conhecimento em que o sujeito é investido pelo conhecimento, o qual é apenas válido para a relação com os seres enquanto esteja situado em uma relação ética, o outro permanecer totalmente fora de mim. (LOVO, 1999, p. 06, tradução nossa).
\end{abstract}

A ética como filosofia primeira se sustenta exatamente no argumento de que ela é anterior à ontologia. O outro aparece como a nova "razão" que fundamenta o Eu, e o "eu" da relação descobre a primazia da responsabilidade que surge na epifania do encontro e da consciência de que a liberdade é posterior a essa responsabilidade que incumbe o sujeito - o eu - da relação. Atesta o filósofo que "desde que o outro me olha, sou por ele responsável, sem mesmo ter que assumir responsabilidades a seu respeito; a sua responsabilidade incumbeme. Isto quer dizer que sou responsável pela sua própria responsabilidade” (LEVINAS, 1982, p. 88).

\title{
O "MINEIRINHO" DE CLARICE LISPECTOR: O FATO HISTÓRICO E RELATO LITERÁRIO
}

No início da década de 60 do século passado os jornais do Rio de Janeiro noticiavam o fim da perseguição e a morte do facínora José Miranda Rosa - cujo apelido o nomeava de Mineirinho. Era considerado pelas autoridades e pela população local um homem perigoso. A busca contava com mais de trezentos policiais, para minar as possibilidades de fuga do assaltante, o qual já havia fugido de sua prisão. Encontrado pela polícia, foi alvo de diversos disparos, sendo atingindo por treze tiros:

\footnotetext{
Com uma oração de Santo Antônio no bolso e um recorte sobre seu último tiroteio com a Polícia, o assaltante José Miranda Rosa, "Mineirinho", foi encontrado morto no Sítio da Serra, na estrada Grajaú-Jacarepaguá, com três tiros nas costas, cinco no pescoço, dois no peito, um no braço esquerdo, outro na axila esquerda e o último na perna esquerda, que estava fraturada, dado à queima-roupa, como prova a calça chamuscada. (WEGUELIN, 1962 apud ROSENBAUM, 2010, p. 02).
}

O relato da citação supracitada não só revela a morte de Mineirinho, como também a maneira brutal como foi assassinado. A essa maneira de se morrer, Clarice Lispector 
demonstra não só compaixão como também a noção de que existe um preceito ético, anterior à existência de qualquer sujeito que impede que ao outro se mate - mesmo que o outro seja classificado como bandido. Ainda que essa noção ética exista, ela parece estar petrificada pela força da violência ou impedida de ser recordada nas relações interpessoais, e em maior grau nas instâncias sociais. Pode-se constatar que a ética expressada no discurso literário da autora tem a capacidade de criar um horizonte de compreensão e reconhecimento do caráter humano. Se a consciência ética estivesse presente no horizonte da humanidade como um elemento primordial, estaríamos possivelmente em processo de autoavaliação constante e possibilitando o lugar de existência humana em suas diversas faces e nas interpelações face a face. Essa ideia consta na citação abaixo, enquanto Clarice se depara com a notícia do assassinato e conversa com sua cozinheira:

Com alguma raiva de mim, que estava mexendo na sua alma, respondeu fria: "O que eu sinto não serve para se dizer. Quem não sabe que Mineirinho era criminoso? Mas tenho certeza de que ele se salvou e já entrou no céu". Respondi-lhe que "mais do que muita gente que não matou". Por quê? No entanto a primeira lei, a que protege corpo e vida insubstituíveis, é a de que não matarás. Ela é a minha maior garantia: assim não me matam, porque eu não quero morrer, e assim não me deixam matar, porque ter matado será a escuridão para mim. Esta é a lei. (LISPECTOR, 2016, p. 386).

A visão ética da escritora pode auxiliar na decodificação e aproximação da ética filosófica de Emmanuel Lévinas, por meio da crônica em análise, visto que se trata de uma história que revela o espanto diante do assassinato de um homem criminoso, um facínora, como relatado, e mesmo a esse tipo de homem se revela uma exigência ética, porque a ética como filosofia primeira não se recusa a ninguém; ainda que seja negada, ela é o instante da existência em que vê e promove o humano ao encontro do outro humano.

Uma promoção humanizadora que foi negada à constituição humana de Mineirinho diante de sua morte, e que agora precisa ser suportada por aqueles que emergem frente à proposição ética, devido a própria subjetividade ir ao encontro responsável com o outro, enquanto têm-se o peso do existir frente a um assassinato. A ética pode acrescer à condição humana o argumento experiencial de que é enquanto se vive que se pode salvar o outro.

\footnotetext{
Mas há alguma coisa que se me faz ouvir o primeiro e o segundo tiro com um alívio de segurança, no terceiro me deixa alerta, no quarto desassossegada, o quinto e o sexto me cobrem de vergonha, o sétimo e o oitavo eu ouço com o coração batendo de horror, no nono e no décimo minha boca está trêmula, no décimo primeiro digo em espanto o nome de Deus, no décimo segundo chamo meu irmão. $\mathrm{O}$ décimo terceiro tiro me assassina - porque eu sou o outro. Porque eu quero ser o outro.
} 
Essa justiça que vela meu sono, eu a repudio, humilhada por precisar dela. Enquanto isso, durmo e falsamente me salvo. Nós, os sonsos essenciais. (LISPECTOR, 2016, p. 386-387).

\section{A ÉTICA COMO FILOSOFIA PRIMEIRA EM O MINEIRINHO}

A filosofia de Lévinas e a literatura de Clarice Lispector são indicativos de um olhar transdisciplinar sobre as realidades e seus temas cotidianos. Ambas as áreas estão entre a criação e a interpretação, gerando constantemente um lugar com privilégios à abordagem da alteridade, do Outro em questão. Por isso a tentativa de interpelar ambos os autores, pois se encontra uma mentalidade aberta ao Outro enquanto conhecimento de si mesmo. O Outro me dá a conhecer em seu interpelar, um conhecimento inesgotável enquanto autoconhecimento. A sua face torna-se um elemento imagético que inaugura o "eu" do sujeito, enquanto descobrem-se e ampliam-se as questões que nos incumbem por meio da alteridade como uma atividade de busca constante pela ética entre os indivíduos.

O espanto gerado diante da barbárie de Mineirinho lançou a autora à busca de argumentos - também éticos - que justificassem (ainda que injustificável) o assassínio, porque a cena lhe parecia surreal, como algo que não pertencesse à realidade a qual todos deveríamos viver. Sua angústia transpunha seu lugar de acomodação, uma angústia que a lança à angústia existencial, ao problema filosófico. Enquanto tentava aproximar-se do sentir da experiência vivida por outrem, identifica-se que nesse momento incorporava também a responsabilidade ante o Outro - esse Outro inteiramente marginalizado, excluído, passível à violência, "o outro é o oprimido, que se chama de índio, de camponês sem terra, de marginalizado nas periferias dos grandes centros urbanos, de desempregado, de pobre do povo que clama por justiça. A revelação desse outro exige uma correspondente práxis libertadora” (SIDEKUM, 2005, p. 05).

Essa responsabilidade em sua constante manifestação lança-nos ao próximo, sem que se tenha que tomar essa decisão. A responsabilidade é anterior à liberdade, se instaura justamente na letra da narrativa literária: "O décimo terceiro tiro me assassina — porque eu sou o outro. Porque eu quero ser o outro.” (LISPECTOR, 2016, p. 387). O Outro é comunicativo, nos lança a interjeição da relação - interjeição irrecusável que comunica seu lugar de fala e recusa ao direito de outrem de agir sobre ele, ou transformá-lo em um tema racionalizado, ou ainda, recusa-se a voz e ao corpo que mata. "No face a face, o rosto aparece não como significado, ou conteúdo a ser explorado, como já foi dito de maneira diferente anteriormente, mas surge como epifania (aparição transcendente), ou como significação, e é 
exatamente neste momento que o rosto "fala'." (SOUZA, 2019, p. 5). O rosto do Outro diz, possui o ordenamento do "não matarás", que em Lévinas aparece da seguinte maneira:

O “Tu não matarás" é a primeira palavra do rosto. Ora, é uma ordem. Há no aparecimento do rosto um mandamento, como se algum senhor me falasse. Apesar de tudo, ao mesmo tempo o rosto de outrem está nu; é o pobre por quem posso tudo e a quem devo tudo. E eu, que sou eu, mas enquanto primeira pessoa, sou aquele que encontra processos para responder ao apelo. (LEVINAS, 1982, p. 81).

E, por conseguinte, a autora na tentativa de responder a esse apelo ético que a incumbe e a torna responsável pelo Outro, lança-se ao fato literário, e toma consciência no rosto de Mineirinho, o pressuposto vocativo do "não matarás":

\footnotetext{
Até que treze tiros nos acordam, e com horror digo tarde demais — vinte e oito anos depois que Mineirinho nasceu - que ao homem acuado, que a esse não nos matem. Porque sei que ele é o meu erro. E de uma vida inteira, por Deus, o que se salva às vezes é apenas o erro, e eu sei que não nos salvaremos enquanto nosso erro não nos for precioso. Meu erro é o meu espelho, onde vejo o que em silêncio eu fiz de um homem. Meu erro é o modo como vi a vida se abrir na sua carne e me espantei, e vi a matéria de vida, placenta e sangue, a lama viva.

Em Mineirinho se rebentou o meu modo de viver. Como não amá-lo, se ele viveu até o décimo-terceiro tiro o que eu dormia? Sua assustada violência. Sua violência inocente - não nas consequências, mas em si inocente como a de um filho de quem o pai não tomou conta. (LISPECTOR, 2016, p. 387).
}

A ética como filosofia primeira aparece em Clarice Lispector quando ela vai em direção a Mineirinho como seu Outro que deveria estar sob sua responsabilidade, sendo, portanto, capaz de suscitar a clareza de que ela poderia ser esse Outro. Por isso trata de relatar sua confissão quando traz o elemento do erro. Tão somente sabe-se da própria responsabilidade quando o erro torna-se visível e gritante. Esse encontro entre o sujeito-outro, em Lispector, evidencia sua narrativa como uma proposta de significação. O criminoso já está morto, e esse fato não tira a responsabilidade. $\mathrm{O}$ rosto do outro, mesmo diante do corpo morto, não esgota sua significação. O poder que acredita exercer aquele que mata, torna-se um pseudopoder. "O assassino exerce um poder sobre aquilo que escapa ao poder. Ainda poder, porque o rosto exprime-se no sensível; mas já impotência, porque o rosto rasga o sensível. A alteridade que se exprime no rosto fornece a única matéria possível à negação total." (LÉVINAS, 1980, p. 167).

O rosto pode ser evidenciado pela capacidade que possui o ser humano, além da categoria lógica, em contemplar as situações ao seu redor. O contemplar filosófico provoca reações na pessoa que contempla, pois cabe a essa capacidade gerar um posicionamento 
filosófico. A autora, ao descrever sua reação diante da morte de um criminoso, narrou também seu conflito ético, existencial, por assim dizer, filosófico. Assumiu uma posição antes impensada, no entanto uma posição que lhe arrebatou a um discurso filosófico: pensar, sentir e reagir contra a postura social - a de querer um criminoso morto.

Seguindo essa perspectiva, a contemplação do rosto é uma contemplação ética, que fala no silêncio "não matarás" enquanto o sujeito responde "eis-me aqui". É uma contemplação que envolve a liberdade e a subjetividade. A interrupção ética por meio das relações abusivas fragmenta e afeta a capacidade de conhecimento e contemplação do Outro. Isso nos impede de escutar com profundidade o Outro que se revela e se comunica em seu rosto. A morte de Mineirinho fez a escritora escutar e tentar descrever por meio da palavra, como uma isca que tenta atrair para trazer à tona o que se fisgou, de uma maneira literária e filosófica, para desestabilizar a expectativa ao trazer à luz o objeto que se rendeu e se revelou.

Nesse caso, a alteridade está como assunto-chave nas reflexões da escritora. A alteridade se oferece como o meio de salvá-la da ambiguidade de defender, enquanto "deveria" acusar o criminoso da crônica em tela. Rosenbaum (2010, p. 11) compreendeu a escritora ao afirmar claramente que "Mineirinho se inocenta ao longo da crônica, passando de criminoso a vítima. Por essa inversão final, a autora funda uma ética do humano que, ao contrário dos sonsos essenciais [...] resta ocupar o silêncio, pelo ato criador da escrita, de quem não pode mais dizer nada".

A interpretação de Clarice Lispector pode ser apreciada por meio de um discurso místico, no entanto se estabelece melhor como uma decifragem filosófica do existir humano, dado a sua profundidade na causa de um homem condenado pela sociedade. $O$ espanto, gerador da literatura e da via filosófica sugerida, pode se apresentar ou se interpretar por meio do mesmo espanto que se manifesta no contato com o outro, que não se reduz, nem tematiza.

A ética da alteridade não alterará a violência cometida contra o Mineirinho, mas será guia nas relações, no despertar do sujeito em seu encontro com tantos outros sujeitos, sua manifestação e aceitação da responsabilidade frente à coexistência, a essa existência participativa e recreativa da subjetividade, dada na interação Eu-Outro. Porque enquanto a notícia da morte do Mineirinho cria e aumenta o abismo entre o Eu e o Outro, a autora constrói uma ponte em um espaço totalmente inconveniente que permite, na travessia, averiguar o intangível e o inapreensível, para arrebatar o abismo sob outro ângulo: o ângulo da alteridade. 
Clarice Lispector vivenciou a dor, a literatura e a filosofia da morte do Outro pelo noticiário. Lévinas foi um filósofo que vivenciou o horror, a violência e a supressão da existência do Outro quando cativo durante cinco anos na segunda Guerra Mundial. Esse foi, por assim dizer, o seu "locus" - lugar - de produção filosófica.

\begin{abstract}
Os anos que se seguem na vida de E. Levinas são muito difíceis e também marcam seu pensamento filosófico. Assim, em 1939, ao continuar seus estudos em Paris será deportado para sofrer em cativeiro durante cinco anos em um "fronstalag" na Bretanha e depois em um campo de concentração na Alemanha. Durante os cinco anos de cativeiro (1940-1945), Levinas aproveitou muito para ler, mas principalmente para escrever. Portanto, grande parte dos trabalhos publicados em 1947, Da existência ao existente e Tempo e o outro foram escritos durante esse cativeiro. [...] Ou seja, a filosofia não tem outro destino senão ser moral ou ética. (LOVO, 1999, p. 03, tradução nossa).
\end{abstract}

Clarice Lispector e Lévinas estão unidos na escrita, literatura e filosofia, como meio apto para a denúncia da desumanização e para o desenvolvimento de uma perspectiva que contrarie o que pode desconstituir o humano em sua existência. Lispector resgata em "Mineirinho" o ser humano que a humanidade desprezou; Lévinas resgata, na ética como filosofia primeira, os dois seres em questão, o Eu e o Outro, e a indissociável responsabilidade que lhes incute.

A autora tem diante de si uma narrativa de dor e sofrimento. Seria mais cômodo não parar-se diante daquilo que aparta da tranquilidade, do que é sinônimo da felicidade tão ilusoriamente desejada. Elevar o fato a uma narrativa literária com arguições filosóficas significa rejeitar a matéria do esquecimento que é o próprio esquecer, tornando a causa um fato passado, sem vida. Trazer à palavra escrita o sofrimento e a procura de respostas diante do pulular dos porquês, recorre-se a uma função filosófico-literário: evitar que o esquecimento absorva a história e edite a matéria factual em sua narrativa sob o véu da farsa. Assim, manteremos a consciência desperta contra o esquecimento que faz deslembrar que o ser humano em seu existir, triste ou feliz, deve simplesmente existir. Recorrer à filosofia para extrair de um texto literário o poder que se tem ao recordar um fato e seus argumentos é evitar que sejamos dominados por um poder que pode apagar nossa memória mais transcendente: a memória da alteridade, da ética como filosofia primeira. 


\section{REFERÊNCIAS}

LÉVINAS, Emmanuel. Ética e infinito. Lisboa: Edições 70, 1982.

LÉVINAS, Emmanuel. Totalidade e infinito. Lisboa: Edições 70, 1980.

LISPECTOR, Clarice. Mineirinho. In: LISPECTOR, Clarice. Todos os contos. Rio de Janeiro: Rocco, 2016. p. 386-389.

LOVO, Carlos Mariano. La etica como filosofia primera en E. Levinas. Rev. Universidad Francisco Gavídia, San Salvador, n.1, jan.Ifev., 1999. Disponível em:

http://www.ufg.edu.sv/ufg/theorethikos/Enero99/carlos.html. Acesso em: 10 ago. 2019.

ROSENBAUM, Yudith. A ética na literatura: leitura de "Mineirinho", de Clarice Lispector. Estud. av. São Paulo. v. 24, n. 69, p.169-182. 2010. Disponível em:

http://www.scielo.br/pdf/ea/v24n69/v24n69a11.pdf. Acesso em: 12 ago. 2019.

SIDEKUM, Antonio. Liturgia da alteridade em Emmanuel Levinas. Utopìa y Praxis

Latinoamericana, Maracaibo, v. 10 n.31, dez. 2005. Disponível em:

http://ve.scielo.org/scielo.php?script=sci_arttext\&pid=S1315-52162005000400007. Acesso em: 08 ago. 2019.

SOUZA, Lourival Robty Santos. Alteridade feminina. Sapere aude, Belo Horizonte, v. 10 n. 19, p. 389-397, jan./jun. 2019. Disponível em:

http://periodicos.pucminas.br/index.php/SapereAude/article/view/19966/14984. Acesso em: 30 jul. 2019. 